\title{
$5-2018$
}

\section{Does inequality erode generalized trust? Evidence from Romanian youths}

Paul E. Sum

University of North Dakota, paul.sum@UND.edu

Gabriel Bădescu

\section{How does access to this work benefit you? Let us know!}

Follow this and additional works at: https://commons.und.edu/pssa-fac

Part of the Political Science Commons

\section{Recommended Citation}

Paul E. Sum and Gabriel Bădescu. "Does inequality erode generalized trust? Evidence from Romanian youths" (2018). Political Science \& Public Administration Faculty Publications. 3.

https://commons.und.edu/pssa-fac/3

This Article is brought to you for free and open access by the Department of Political Science \& Public Administration at UND Scholarly Commons. It has been accepted for inclusion in Political Science \& Public Administration Faculty Publications by an authorized administrator of UND Scholarly Commons. For more information, please contact und.commons@library.und.edu. 


\title{
Does inequality erode generalized trust? Evidence from Romanian youths
}

\begin{abstract}
Generalized trust is a critical component of liberal democratic citizenship. We evaluate the extent to which exposure to socioeconomic inequality erodes trust among Romanian youths. Using national survey data of Romanian eighth-grade and high school students, we evaluate this effect as a product of socioeconomic diversity within the classroom, controlling for the social status of the students as well as socioeconomic inequality within the community where the school is located. Our analysis shows that generalized trust is higher for students in higher grades. However, despite this maturing effect, students exposed to greater levels of socioeconomic diversity have significantly lower levels of trust. The effect is particularly acute for students in the ninth grade. This finding holds when controlling for socioeconomic diversity and polarization in the community. The result reinforces the idea that generalized trust develops early in one's life and is quite stable, although a major life transformation, such as entering high school, may alter trust depending on the social context.
\end{abstract}

Key words: generalized trust, economic inequality, adolescents, Romania, education 
The relationship between generalized trust and income inequality has been shown consistently cross-nationally through studies of aggregate measure of the two (Bjørnskov 2007; Gustavsson and Jordahl 2008; Knack and Zak 2002; Olivera 2015). Where the gap between rich and poor is wider, individuals tend to be more skeptical of people they do not know. Since generalized trust is positively associated with social cohesion, economic vitality, and democratic governance, a number of negative social consequences result, at least indirectly, from socioeconomic inequality (Uslaner 2002). Despite the implications, we know little about the causal mechanism that operates between socioeconomic diversity and generalized trust. The relationship presumes that one's exposure to income disparity and status differences will decrease one's faith in strangers. To what, precisely, is one being exposed that begets the outcome? What contextual features accompany this process?

We tackle these large questions within a relatively small confine. Using national data collected from adolescents in Romania, we investigate levels of generalized trust among high school students taking into account their exposure to income inequality in their classrooms, as well as their communities, relative to their family wealth. We are particularly interested in two questions relevant to the relationship between inequality and trust among Romanian adolescent population: Does exposure to income inequality in the classroom lower generalized trust? To what extent can we distinguish between observed classroom effects and the impact of inequality found in the locality coexisting with the high school experience?

Despite significant gains in understanding the macro phenomenon of trust, gaps remain in the literature, particularly with regard to understanding how different contexts may trigger changes in trust levels (Dinesen and Sønderskov 2018). A shortcoming in the literature has been to underspecify the context through which trust develops and is maintained. We consider eighth to twelfth grade students as an intermediate population isolating the particular context of their classroom experiences. Our data spans the transition from elementary to high school which means that many students are exposed to a different socioeconomic configuration after the eighth grade. Additionally, our national sample of students offer variance from which we may observe levels of trust within higher or lower income disparity classrooms. With few exceptions, Stolle and Hooghe (2004) being one, studies of generalized trust focus attention on adults and usually do so through surveys. We know that social and political attitudes begin to solidify during early 
adolescence (Prior 2010). Exposure to different social contexts, especially at this age, is critical in shaping core attitudes (Andolina et al 2003; Niemi and Sobieszek 1977).

Generalized trust is a core disposition that remains relatively stable throughout one's lifetime. Yet, evidence suggests that over the past decades, aggregate levels of trust have steadily declined among European adolescents (Rahn and Transue 1998). Youths may not fully understand the values that hold a community together and tend to be less involved, and so lower trust is to be expected. However, a trend of declining trust among European youths may be associated with changing values on a boarder level, and these have been linked to rising income inequalities may be associated with changing values (Layte 2012). In Romania, the postcommunist generation has witnessed inequalities in the wake of increased temporary and commuter migration patterns in search of material security, and this may suggest that core values within the country are in flux (Stan and Erne 2014).

Romania is a low-trusting country for a number of reasons. Generalized trust in postcommunist countries tends to be low, and Romania is no different in this respect (Uslaner 2003). A lackluster economy, weak political institutions, and entrenched clientelism contribute to low levels of generalized trust (Jamal and Nooruddin 2010). In fact, Romania has consistently displayed some of the lowest levels of trust in Europe. Our population did not experience communism and have known Romania as a European Union country for most of their lives. Studying this cohort provides an excellent opportunity to evaluate how trust develops within a relatively new, sometimes struggling, democratic country.

To sustain its liberal democratic regime, a deepening of democratic values among citizens is considered a necessary condition (Diamond 1999, 64). Generalized trust is one of those values and correlates well with others, such as tolerance (Sullivan and Transue 1999). Given the illiberal direction of politics in the region, Romania is instructive as a case that has not succumbed to populist leadership. On a more general level, our results contribute to the understanding of how trust emerges among this age group. Despite vastly different regime experiences between Eastern and Western European countries, trust develops through similar processes and individual motivations (Uslaner 2003, 82). Thus, Romanian adolescent experiences may inform our understanding of trust among this population within Europe.

The transition between elementary and high school is a pivotal development point within an individual's life, which sets one on a particular life span trajectory impacting, among other 
things, one's perceived role as a citizen (Baltes and Nesselroade 1984). The experience of entering high school, however, is highly dependent on social context especially realized as a product of social inequalities. Elder et al. (2003) emphasize that transitioning to high school leaves students psychologically and socially vulnerable, and thus, they are much more likely to reproduce social inequalities as a coping mechanism. Our study views this possibility through the lens of generalized trust, and thus, we speak to the broader themes democracy and citizenship at a critical juncture in social development.

\section{Democratic governance and income inequality}

In recent years, actors in new and old democracies alike have adopted authoritarian qualities, both in rhetoric and action, prompting some to refer to a global democratic recession (Diamond 2015; Puddington 2010; Kurlantzick 2011). Although Levitsky and Way (2015) caution that the magnitude of the trend may be overstated in the face of global comparisons over time, there can be little doubt that populist movements and radical right parties in European democracies have influenced public discourse and enjoyed pockets of strong support (Mudde 2013). In Europe, the governments of Austria, Hungary, Poland, and Slovakia have incorporated nationalist, sometimes neo-rightist, policies that are seeping into their political institutions (Greskovits 2015). The rise of illiberal politics coincides, on a global level, with growing income inequality although the trend varies depending on the country (Piketty 2014; Keeley 2015; Roine and Waldenström 2015; Bourguignon 2015).

Romania has not been entirely immune to pressures toward illiberal democratic governance in the face of economic inequality. The European Union has seen relative stability in income distribution with an average Gini coefficient hovering near 31.0 for a decade. Contrast Romania, which has averaged a Gini coefficient of 35.2 over the same period with its latest figure being 37.4 in 2015 (European Commission 2017). ${ }^{1}$ During the 1990’s, the Romanian Gini coefficient level was on par with Sweden at 22.7. Using the income quintile ratio (S80/S20) as an alternative measure, Romania (= 7.2) is well above the European Union (=5.2) average and one of the most unequal countries among the 28 members. Coinciding with economic inequality, Romania faces recurring constitutional crises often tied to its culture of corruption and clientelism that subverts the rule of law (Deletant 2015; Gallagher 2005). 
When scholars attempt to explain the relationship between democracy and inequality, they stress the impact of democratic rule on resource distribution rather than vice versus (Huber and Stephens 2012; Acemoglu et al 2013). Some scholars have begun to rekindle the classics' interest pondering the extent to which levels of social inequality can be sustained within a liberal democracy (Stiglitz 2012; Wade 2013; Bartels 2016; Jung and Sunde 2014; Kang 2015). In the most general terms, the literature maintains that inequality is hurtful to democratic governance in both developed and post-transitional political systems (Fukuyama, Diamond, and Plattner 2012). Even in robustly institutionalized polities that benefit from high growth rates, rising economic inequality converts into higher levels of political inequality accompanied by lower levels of trust in established institutions and a willingness for the socially dislocated and downwardly mobile to entertain openly anti-democratic platforms. Yet, little consensus is found regarding how these causal mechanisms operate, endogeneity problems, and omitted relevant variables; differences in conceptualization and measurement contribute further to the discord (Savoia, Easaw and McKay 2010). Our approach is to examine a specific context as one element of the broader tapestry.

\section{Generalized trust and democracy}

Generalized trust is one component of what we might refer to as "democratic values" (Warren 1999). Having faith in people who you do not know encourages cooperative behavior making it easier to overcome collective action problems (Coleman 1990; Colquitt et al 2007; Newton 1999; Putnam 1993; Uslaner 2002). By reducing social ambiguity, trust also facilitates contingent and complex decision-making (Shapiro 1987, Costa 2000), risk-taking behaviors become more common because trust builds a sense of assurance (McAllister 1995; Six 2005), which in turn, lubricates social and economic relationships (Fukuyama 1995; Hollis 1998). This sequence too is aided when economic disparities are low.

Generalized trust is at the foundation of social capital, based on the perception of commonly held values (Marschall and Stolle 2004; Putnam 2000; Uslaner 2002; Woolcock 2001). Included among these values are reciprocity, tolerance, and civic morality, and generalized trust fosters and reinforces each (Bjørnskov 2007; Letki 2006; Sullivan and Transue 1999). Broadly speaking, these values contribute to social cohesion, and all are more readily achieved in an environment where economic diversity is not extreme. 
Optimism is also associated with generalized trust (Uslaner 2002). People who have faith in strangers tend to be more hopeful for the future. They are more likely than those who are less trusting to believe when things are going well, that they will remain so, and when faced with challenges, things will get better. Theoretically, their confidence in the future parallels a confidence they have in themselves suggesting empowerment and a heightened sense of control over their situation. In other words, those who trust possess a sense of self-efficacy, tending to believe they make their own way and shape the future. Taken together, these qualities constitute a profile of democratic citizenship that, within sustained democracies, is reproduced in each generation. However, once trust begins to unravel, it does so quickly, and rebuilding generalized trust takes time.

The cycle toward good citizenship, which includes generalized trust, begins at an early age and transitions punctuate the process of human development (Shanahan 2000). The transition from eighth grade to high school represents one of these transitions, but "adaptation to the new situational imperatives of high school may be difficult, particularly immediately following the transition” (Benner 2011, 316). Socioeconomic disparity increases the challenges students face, and generalized trust may suffer from the exposure to such inequality.

\section{Socioeconomic inequality and generalized trust}

The negative relationship between economic inequality and generalized trust has much support (Bjørnskov 2007; Gustavsson and Jordahl 2008; Knack and Keefer 1997; Knack and Zak 2002; Olivera 2015; Uslaner 2002; Zak and Knack 2001). The theoretical premise behind studies that link economic inequality to trust is that inequity builds walls among socioeconomic classes. As more and more people enter the income brackets on extremes (either high or low), at the expense of the middle class, economic standing comes to represent a class-based, in-group fate. The values that bind those in the lower economic rungs diverge from those at the top, and the absence of shared values breeds suspicion (Uslaner and Brown 2005). Perceptions of competing value systems based on socioeconomic status encourages further social separation and reinforces distrust. However, “differences among people in the bottom half of the income distribution appear to have a particularly strong effect on trust” (Gustavsson and Jordahl 2008, 349). Thus, the erosion of trust need not occur evenly across social groups. Moreover, individual experiences 
and other features of the social environment may mitigate or even negate the negative effects of income inequality (Borgonvi and Pokropek 2017).

Income distribution conceptualizes a broader idea rooted in the structure of social class and the role that status differences play in shaping social attitudes (Wright and Perrone 1977). Romania is a case that confirms the pattern that low levels of trust on an aggregate level are associated with greater levels of income inequality. Estimates of income distribution, however, may not provide the best measure of social status or class, especially within a post-communist context. National measures of income distribution tend to be rigid across time, if they are measured consistently at all. The somewhat static measures of income distribution, e.g. Gini coefficients, pair with observed rigidity in levels of generalized trust (Uslaner 2002). As a result, identifying temporal trends for the relationship between inequality and trust have suffered from a lack of variance. In Eastern Europe, we also see income inequalities vary to a greater degree with regard to age brackets, education levels, and regions more than what we observe in Western Europe (Heyns 2005).

We address these measurement shortcomings in a variety of ways. First, we use alternative measures to income for estimating inequities in the community, namely patterns educational attainment and housing stock. Secondly, although most of the analysis uses crossnational data, we have a longitudinal component that helps sort out, if not resolves, some of the endogeneity problems. Finally, we consider the local context of individual schools, as a mezzolevel analysis, instead of relying on a national estimate.

A number of studies on generalized trust show that estimating "exposure" to diversity is best achieved through research designs that capture this process on a local level where individuals experience it. For example, in the United States levels of generalized trust in mixedrace neighborhoods tend to be lower than in areas that are more homogeneous, but only when measures of local income distribution are included within the analysis (Alesina and La Ferrara 2005). In Denmark, ethnic diversity measured locally relates to declining levels of trust in those neighborhoods (Dinesen and Sønderskov 2012). In Australia, generalized trust is lower in ethnically diverse communities, again measured locally, especially when linguistic differences mark those communities (Leigh 2006). Sweden similarly shows that when inequality is measured on a local level, a more nuanced picture of its negative effect on trust is revealed (Gustavsson and Jordahl 2008). 
Building on these findings, our analysis evaluates the effect of socioeconomic diversity on generalized trust within a localized context, the high school classroom. The transition from elementary school to high school can be a difficult one for many students. Disruptions in psychological functioning are not uncommon, and the negative effects are accentuated for minorities (Benner and Graham 2009). In Romania, students enroll in elementary school based on geographic residency, while high schools require an exam process placing students according to aptitude so the geographic range of the student-body is wide. High schools draw from a broader range of neighborhoods, which tends to increase economic diversity in enrollments, depending on the locality and competitiveness of the examination. For many incoming high school students, their cohort are mostly strangers, leading to a number of negative academic and social outcomes, at least in the short-run (Cohen and Smerdon 2010). Through our design, we are able to consider how generalized trust changes when students confront an environment populated with many unfamiliar faces, and if exposure to economic diversity has an independent effect on levels of generalized trust for our population.

Although we are interested in students, we draw a national sample of schools. This allows us to take advantage of the variance among districts in terms of socioeconomic diversity. We consider how a student's exposure to the income diversity among classmates, relative to his or her financial standing, affects generalized trust. We also broaden our lens and consider the extent to which socioeconomic diversity within the community may independently influence trust among students. We employ two measures of social diversification that include local education levels and housing stock in the community, as well as the extent to which that socioeconomic diversity is polarized.

Our findings contribute to the ongoing debate about the relative stability of generalized trust and the possibility of intentional change. If the analysis shows that exposure to socioeconomic diversity does indeed influence trust levels, the finding would be consistent with those who hypothesize that generalized trust varies somewhat fluidly across contexts and experiences (Dinesen and Sønderskov 2012). On the other hand, if exposure is not a significant factor in explaining levels of trust over time, the finding lends credence to a cultural understanding of generalized trust, which maintains that trust is highly stable across experiences and time (Uslaner 2002). 


\section{Research design and data}

We anticipate that exposure to difference will depress generalized trust. Inequality is manifest throughout social life, and yet, causal mechanisms that influence trust are difficult to identify. By isolating specific contexts, we begin to untangle this relationship. Our design uses Romanian elementary students (eighth grade) and high school students (ninth to twelfth grades) and takes into account multiple levels of exposure to economic diversity at school as well as that found in the community. The design allows us to identify the extent to which students who are exposed to socioeconomic inequality in the classroom experience decreases in generalized trust, controlling for inequality in the community. In addition, we consider mediating factors linked to individual-level social traits with particular attention given to family income and parents' education levels as estimates for social class and status.

To model the relationship between exposure to socioeconomic diversity and generalized trust among youths, we utilize a Romanian national survey data set collected over a four-year period: 2008-2012. The multilevel data set includes individual student responses, information about the school, and information about the school district and community. The survey (RO survey) includes between the eighth and twelfth grades. The survey was applied in 2010 and included 5,862 respondents, representing 86 schools from 70 localities. The sample selected classes and was drawn through a random process stratified by type of school (high school and vocational school), cultural region, and locality size (rural, town $<100,000$, and urban $>$ 100,000). Once a class was selected, all students in that class were asked to respond. This survey has a panel subsample (HS panel) that included ninth graders, interviewed after one month of their first year of high school, and interviewed again shortly before the school year ended. The panel subsample yielded 2,023 respondents, representing 45 schools from 36 localities. The average school size for the entire sample is 500 students.

The sample is national in scope and representative of all high school students in Romania with approximately 90 percent ethnic Romanian, six percent ethnic Hungarian, and three percent Roma and others. The mean number of respondents per class is 24 (median=25) and resulted in an 80.1 percent response rate, including the panel component. Our sampling frame, students enrolled in school captures most, but not all Romanian adolescents. The proportion of youth who are aged 15 and 16 and who attend Romanian schools is 89.8 and 88.3 percent respectively. That proportion goes down for 17-year-old students at 74.7 percent and decreases further for 18-yearolds at 72.1 percent (UNICEF Romania 2014, 20). 
The design is appropriate for our primary research questions regarding the relationship between exposure to income diversity and generalized trust among high school students. Using "the class" as our sampling unit allows us to observe trust on the individual level knowing the intensity of income difference that is present in the classroom. We integrate community level data, derived from the 2012 Romanian census, to the individual and classroom-level items in both data sets. ${ }^{4}$ The measures allow us to control for inequality within the community where the school is located. Thus, our multilevel models address some of the endogeneity problems associated with the community context of the school. Nevertheless, our models are necessarily limited. Any number of factors influence generalized trust but our data, and as a result, our analysis isolate the possible effect of exposure to socioeconomic diversity. We control for characteristics available in our data: respondents' background (family income and parents' education) and the presence of a university in the community.

\section{Hypotheses and measures}

We develop three hypotheses and test these using data collected from the students. The first hypothesis centers on their experiences within the classroom. Attitude development occurs rapidly during adolescence and often the core values associated with these attitudes endure into adulthood (Niemi and Sobieszek 1977; Stolle and Hooghe 2004). Families are critical to this process, but we also know that the school setting exerts influence over the attitudes among youth. Schools are an intermediary institution bridging family and community, and as such, expose students to a broader social context. For many students, exposure to more diversity includes cultural differentiation based on different social categories, and shaping their world views in the process (Bourdieu and Passerson 1977). Educational stratification predicts levels of social mobility suggesting that socialization within the school reflects students' later experiences as young adults (Breen and Jonsson 2005). Generally speaking, higher levels of ethnic diversity are associated with lower levels of trust (Dinesen and Sønderskov 2018). Our first hypothesis extends this relationship and asks if socioeconomic diversity exerts a similar effect on trust.

H1: Exposure to greater degrees of socioeconomic inequality in the classroom results in lower levels of generalized trust 
Most Romanian students who complete eight grades of schooling continue their studies at a secondary school. Elementary school assignment in Romania is determined through residency districting. For high school, students sit for an exam which determines their eligibility for enrollment in a particular high school. As a result, high schools draw from a wider geographic area, depending on the number of options in a particular locality. Coupled with the fact that elementary schools enroll fewer students per grade than high schools, we expect students entering high school to know fewer classmates. A lack of acquaintances has been associated with a number of negative outcomes for students including lower academic achievement (Langenkamp 2009). Although our data show that economic diversity is not systematically higher in high schools compared to elementary schools, we further expect exposure to socioeconomic diversity to have a negative effect because of the new social environment.

We estimate generalized trust using an aggregate index, creating a latent variable, from three observed measures: 1) trust in strangers, 2) trust in people who possess a faith different from one's own, and 3) trust in other ethnicities. High values represent high trust. To test the first hypothesis, we analyze data from our eighth-grade subsample of students separately and aggregate high school students across all years. To measure socioeconomic diversity, we take the self-reported family income of each respondent and calculate the standard deviation of the class mean, a value that we assign to each respondent in that classroom. Thus, we estimate individual levels of trust relative to the level of socioeconomic diversity to which they are exposed based on the configuration of income distribution among their classmates relative to their own station.

Students spend a significant portion of their days in the classroom. Consequently, we expect the exposure to diversity there to have a direct negative effect. However, the measurement of “exposure” is subject to problems related to endogeneity. Although schools cast imperfect reflections of the broader social context, they do not stand in isolation from that community. Therefore, we want to account for socioeconomic diversity within the locality of the school.

Income levels for the community are not available, but the Romanian census publishes the education levels of individuals in a locality as well as size of residences. Although not perfect, education levels parallel socioeconomic status and can be used as a proxy (Cirino et al 2002). With this in mind, we develop two measures of socioeconomic inequality in the community. The first takes the standard deviation of the education level mean for each locality. The second estimate of community-level inequality uses the average size of a residence in square 
meters, taking the standard deviation, for each locality. We expect that socioeconomic diversity within a community will operate similarly to the way it does in the classroom and result in a negative effect on generalized trust. Using the two macro-level variables, we develop a second hypothesis.

H2: Students who attend school in localities where there are greater degrees of socioeconomic inequality have lower levels of generalized trust

Socioeconomic differences in and of themselves may not be the driving force behind generalized trust. Instead, the pattern of diversity may be the determining factor. Polarization is associated with a number of social phenomena, especially with regard to interpersonal relationships (Permanyer and D’Ambrosio 2015). Applied to trust, Uslaner (2011) shows that where socioeconomic polarization is present, defined as communities with significant differences between the wealthy and the poor, trust tends to be lower. Thus, the causal mechanism is not socioeconomic difference per se but type of settlement that breed suspicion. Following this logic, we develop our third hypothesis.

H3: Students who attend school where there are greater degrees of socioeconomic polarization have lower levels of generalized trust

Polarization estimates should meet two characteristics: a partition based on groups defined by "salient social characteristics" and the extent to which groups cluster on that social attribute (Permanyer and D’Ambrosio 2015, 312). Typically, researchers use income as the salient characteristic. However, that data are not available to us. Also, race, ethnicity, or religion might be used, depending on the context and question being investigated. For us, the relative homogeneity of Romania makes these categories unworkable with our sample. Instead, we construct a variable of polarization based on the education level of students' parents within the locality, accepting that while not perfect, education levels capture an aspect of socioeconomic status (Cirino et al 2002). We take the percentage of students in each 0-8 level school with at least one parents whose education level is less than eighth grade completed. From this figure, we subtract the percentage of students who have at least one parent with experience in higher 
education. We then take the standard deviation of the difference to give us our estimate of polarization for localities with at least three 0-8 grade schools.

Parents' education levels and household income allow us to control for each respondent's socioeconomic position (Borgonovi and Burns 2015). Because one of our community inequality measures and our polarization estimate rely on education levels, we also control for the presence of a university within the locality. More than 20 Romanian cities have a major university and many more have satellite or extension campuses. Descriptive statistics for all variables included in our models are included in the Appendix.

\section{Data Analysis}

Trust among Romanian adolescents averages at .36 for our entire sample. However, as Figure 1 shows, there is a maturing effect. Generalized trust for twelfth-grade students is higher compared to those in the eighth grade, although this is not a perfectly linear relationship across five years of adolescence. The two broken lines in Figure 1 shows trust for those students in the lowest and highest quartiles for classroom inequality. Exposure to greater levels of classroom inequality correlates with generalized trust and this holds across all grades, lending support for our first hypothesis.

[Figure 1 about here]

The transition between elementary school and high school is of particular interest since the change represents a new setting for all students, and one where the likelihood is high that many of their colleagues are strangers, not having attended the same elementary school. Yet, the absolute level of trust within the sample is higher among ninth graders compared to those in eighth grade.

The next step in the analysis is to consider the relationship observed in Figure 1 taking into consideration a student's own socioeconomic status influences trust. We cannot rule out a possible indirect influence of a student's socioeconomic status so that inequality in the classroom affects trust differently depending on the background of a student. Table 1 shows the results of a 
cross-sectional Structural Equation Model (SEM) when we subdivide the sample between respondents in eighth grade and those in high school. Our purpose is to compare eighth-grade students to their high school counterparts in terms of the impact that exposure to economic diversity in the classroom has on generalized trust. We control for a respondent's socioeconomic status through self-reported family income and the education levels of parents.

[Table 1 about here]

We find additional support for our first hypothesis in Table 1. Exposure to inequality in the classroom, our chief independent variable, has a negative effect on trust among high school students (standard estimate $=-.137$ ), but such exposure is not a significant predictor among eighth-grade students. The finding reinforces the small difference between trust from the upper and lower inequality quartiles for eighth graders represented visually in Figure 1. Thus, experiencing socioeconomic diversity in high school is somehow different, although we cannot be sure about the nature of that difference.

The finding holds when controlling for a student's socioeconomic background. The education level of the parents of students has a positive, significant effect on generalized trust. Table 1 shows that parental education predicts family income, but the latter does not have a statistically significant independent effect on trust among high school students, suggesting that exposure to economic diversity has a larger negative effect on respondents from a lower socioeconomic background for eighth-graders. For those in high school, the effect is similar but weaker.

To explore the relationship further, subdivide our sample again, including only eighth and ninth graders. We add a binary variable (ninth-grader) to test the proposition that ninth-grader trust is systematically higher than that of eighth graders. We also add an interaction term (ninthgrader * inequality class) to see if inequality in the classroom has a greater, independent effect on ninth graders compared to eighth graders.

Table 2 reports the results from SEM analysis. Inequality in the classroom continues to have a statistically significant negative impact on trust for the subsample, but the effect is 
considerably smaller (standard estimate $=$-.069). For the interaction term (ninth-grade * inequality), the impact on trust is larger with a standard estimate of -.352. The finding is consistent with the notion that for those students entering high school, exposure to greater socioeconomic diversity decreases trust. Nevertheless, the positive standard estimate (.419) for our binary variable, ninth-grader, shows that despite exposure to socioeconomic diversity, those entering high school have higher levels of generalized trust than their eighth-grade counterparts. As seen in Table 1, the social status of a respondent matters. The negative impact of exposure to socioeconomic diversity on generalized trust is magnified among students with low family income and whose parents are less educated.

[Table 2 about here]

Schools do not operate in a vacuum. Based on the results in Tables 1 and 2, we cannot rule out the possibility that exposure to inequality in the classroom is spuriously related to generalized trust, with inequality in the community being the driving force behind the observed effect. We address this potential endogeneity problem with a revision of the model reported in Table 1 so that community-level inequality and polarization are taken into account. The new iteration of the model will test our second hypothesis that students who attend school in localities with greater socioeconomic disparities will have lower trust levels.

We introduce to the model the measure of locality inequality based on education, which is calculated as the standard deviation of the education level among residents in the community. Locality inequality based on housing represents the standard deviation of living space (in square meters) within a locality.

We consider polarization at the community, the subject of our third hypothesis, through the addition of a new variable, "locality polarization," which is the standard deviation of the difference between the percentage of students in each 0-8 level school with at least one parent whose education level is less than eighth grade completed and the percentage of students with at least one parent with higher education. Lastly, we evaluate the impact that the presence of a university has on trust. Although a university alone is not expected to produce inequalities, the 
dependence of two of our community-level variables on education levels suggests that the presence of an institution of higher learning may influence the calculated variables estimating inequality and polarization in the broader social context.

We report the results of SEM analysis for our revised model in Table 3. When controlling for community-level factors, exposure to diversity in the classroom continues to have a negative effect on high school students. This effect extends to eighth-grade students now suggesting a relationship between classroom and locality.

We had hypothesized that community inequality would have a negative effect on students. Table 3 shows that this is not the case. In fact, for both subsamples, the opposite holds: where locality inequality is greater, generalized trust tends to be higher for our student respondents. The presence of a university in the locality also has an independent positive impact on trust among Romanian youth, suggesting that the positive results of the inequality measures are not artifacts of an institution of higher learning in the community.

[Table 3 about here]

The extent to which a community is polarized, the subject of our third hypothesis, conforms to our expectations for the eighth-grade sample but shows the opposite for high school students. The influence is negative among the eighth-grade students (more polarization in the community is associated with lower levels of trust) but positive for the high school students. The diverging impact of polarization on eighth-graders compared to high school students, combined with the greater negative effect of inequality witnessed among those in the eighth-grade sample, suggests that the transition from elementary to high school may be transformational with regard to trust. When controlling for community-level inequality, the socioeconomic status of the respondent does not have as pronounced effect on trust as we saw in Table 1.

Following the logic employed in generating Table 2, we again reconfigure our subsample to include only eighth and ninth-grade students. We rerun the community inequality model with a binary variable representing ninth-graders and an interaction term for ninth-graders and exposure to inequality in the classroom. Table 4 reports the results from SEM analysis. 
When controlling for community inequality and polarization, trust remains higher among ninth-graders compared to eighth-graders as represented by the binary variable (standard estimate $=.252$ ). Inequality in the classroom ceases to hold statistical significance for the subgroup of eighth and ninth graders. However, the interaction term shows that exposure to inequality in the classroom is negative, and statistically significant, among those in ninth grade. In other words, despite generally higher levels of trust overall, students who first enter high school are more susceptible to the negative effect on trust from exposure to socioeconomic diversity in the classroom. Moreover, this tendency has a greater impact among students from a more disadvantaged socioeconomic background.

[Table 4 about here]

Table 4 further shows that when community-level controls for inequality and polarization are included, the independent effect of classroom inequality loses statistical significance, although the interaction term with the binary variable "ninth-grader" remains statistically relevant. Similar to Table 3, locality inequalities correlate with higher levels of trust among the subsample. The level of polarization in the community also loses statistical significance.

Thus far, the analysis reveals that exposure to socioeconomic diversity in the classroom negatively influences generalized trust, and that the effect is acute at the point of transition to high school. However, "exposure” is not an event but a process. Our data includes a panel subsample for students in the ninth-grader. The survey was applied twice to these students. The first application was upon entering high school (time ${ }_{1}$ ) and the survey was applied again at the end of ninth grade (time 2 ). Table 5 shows the results from SEM analysis based on a longitudinal version of the models used above.

According to the Table 5 , trust ${ }_{2}$ is best explained by trust ${ }_{1}$ suggesting stability across the ninth-grade experience. As shown in the Appendix, the mean value of generalized trust among high school students changes very little from trust ${ }_{1}(.36)$ to trust 2 (.37). Exposure to diversity in the classroom contributes to an explanation of trust 1 providing additional support for our first hypothesis. However, for trust 2 , when socioeconomic diversity in the community is not included 
(the left side of Table 5), we are far less confident that classroom exposure is contributing meaningfully to the outcome (standard estimate $=-.051$ with $\mathrm{p}=.08$ ). Adding community diversity variables to the model (the right side of Table 5) eliminates the effect of classroom exposure. Thus, exposure to socioeconomic diversity in the classroom is statistically significant during students' first month or so of high school. After this initial effect, the level of trust is maintained, more or less, during the rest of the first year. Socioeconomic diversity in the classroom ceases to play a statistically significant role in shaping trust levels by the end of the first year (trust 2 ).

[Table 5 about here]

Community inequality also contributes to an explanation of generalized trust at both points in time, although size of residence is no longer a significant factor for trust2. The finding reinforces the positive impact locality-level diversity variables have on trust as shown in Table 2. However, in the panel data, we see a different pattern for polarization from what we saw using the aggregated high school data of Table 3. For both points in time in ninth-grade, students who attend school in more polarized localities tend to have lower levels of trust.

A summary of our main findings are as follows. The level of trust among Romanian adolescents increases as they progress through high school with the greatest gain being observed between eighth grade and high school. Despite this increase, exposure to socioeconomic diversity in the classroom negatively influences individual trust levels. The negative impact affects all students but is stronger among students from a lower socioeconomic position, as measured by family income and parental educational attainment. The effect holds when controlling for community inequality, although the broader environment variables unexpectedly are associated with higher levels of trust. Community polarization has an independent negative impact on trust for eighth and ninth-graders but the opposite effect on older students. When controlling for polarization, exposure to socioeconomic diversity in the classroom maintains its own independent effect. The presence of a university in the locality positively influenced trust. We discuss each of these findings in turn below. 


\section{Discussion}

Three hypotheses have guided our inquiry. Primarily, we are interested in how exposure to socioeconomic diversity in the classroom influences generalized trust among Romanian youth. Our unique data set and research design allow us to test for this effect. Measuring exposure is a difficult task, and our analysis, like many others, is vulnerable to endogeneity. In an effort to counteract the problem, our analysis incorporates measures of inequality and polarization in the locality of the school. We estimate socioeconomic diversity in the locality in two ways: through community education levels and average size of housing. Levels of polarization are measured through patterns of educational attainment.

In absolute terms, we find that the level of generalized trust increases across grade levels. Despite students becoming more trusting of strangers overall, exposure to socioeconomic diversity in the classroom negatively impacts trust. This effect is visible in eighth grade and continues into the high school years regardless of socioeconomic status of a student's family based on income. However, the negative impact tends to be greater among students from lower socioeconomic households.

The finding suggests a situational component to generalized trust. Many studies show how exposure to ethnic diversity lowers trust. We show that socioeconomic diversity has a similar effect, and that the effect impacts those from the lower rungs of society to a greater extent. Thus, trust among youth depends on who you are as well as who your classmates are. Students spend considerable time together in the classroom, and over the course of a year, the exposure to the level of socioeconomic diversity among classmates is considerable. Although our panel component is limited, the results from the analysis are consistent with the idea that negative effect of socioeconomic diversity on trust comes as a bit of a shock but do not carry longer effects, at least in the school setting. Thus, the initial transition to high school is where we see growth in trust in absolute terms but also where we see the most pronounced negative effect from exposure to socioeconomic diversity in the classroom.

Where you are also influences generalized trust. We found that community level indicators produce statistically significant results but not in the expected direction. Communities with higher socioeconomic disparities tend to produce more trusting students. The finding may be a by-product of the measurements we employed: average education levels and size of residence in the community. Romania enjoys a relatively high level of education, so when we see 
inequality through education at a community level, pockets of highly educated persons may be driving the outcome. We address this potentiality by controlling for the presence of a university in the locality, counteracting the potential impact that higher education institutions might have in creating pockets of educated citizens. We find that localities that house universities, indeed, have a positive effect on trust, but employing this control does not eliminate the positive association between community inequality based on education levels and generalized trust.

We use the size of residence, in square meters, as an alternative to educational attainment patterns as an alternative estimate for community inequality. When the standard deviation of the average square footage of living space is larger, we see increased socioeconomic inequality. Large bloc apartment buildings, a legacy of the communist period, remain a dominant form of housing in Romania and apartments vary in size. Measured this way, higher standard deviations may actually reflect localities that have more communist housing bloc units from the former regime, which in turn reflects patterns of development forged under the communist regime. In other words, communities dominated by bloc apartment buildings are associated with areas with greater access to resources and infrastructure, which may be driving the result.

Our analysis also evaluates the extent to which socioeconomic polarization within the locality influences generalized trust. We find that polarization negatively affects the trust on subsamples of eighth-graders and ninth-graders, suggesting a relative sensitivity to polarization of the younger students within our sample. Both groups are transitioning. However, the result may also relate to school districting. Elementary school districts in Romania, like most other places, encompass a smaller geographic area than a high school district. Our measure of polarization, collected through the census, is on the locality level. One or two high schools service most Romanian localities. However, that same geographic unit often includes several (or more) elementary schools. Our polarization measure may capture an uncertainty among elementary and first-year high school students, whereas older high school students have become more familiar with the broader community, and its qualities of inequalities and polarization. Despite the unanticipated results of some our community-level variables, adding locality level factors reveal a significant negative effect of exposure to classroom inequality among eighthgraders, suggesting that locality inequality or polarization may have indirect effects on other contexts, such as the classroom. 
Our results speak to three theoretical issues regarding our understanding of generalized trust. First, we see that trust develops early among youths, reinforcing a finding within the literature, but applied to a new context. Our findings also reinforce the general notion that exposure to diversity has negative consequences for generalized trust. Socioeconomic inequality operates in a way that is similar to what other studies have shown for exposure to ethnic diversity. However, the longitudinal design component points to an important qualification. Exposure to socioeconomic diversity in the classroom has an initial negative impact but a finite one. Students seem to adjust to the diversity with a new, albeit lower, level of trust but continued exposure to this diversity does not drain stocks of trust over time. In this respect, the finding reinforces what we see elsewhere in the literature regarding the relative stability of generalized trust. Levels do not change much over time in our data and exposure to diversity does not have a cumulative effect.

Trust is mutable and dramatic life changes, akin to entering high school, can change a person's level of generalized trust. The first-year high school students' exposure to diversity is immediate and intimate. However, once students settle into the routine of school and develop personal relationships, the impact of such exposure seems to dissipate. The same may hold for exposure to diversity within any number of social contexts. After an initial adjustment, exposure to diversity stops producing the effect. Once individuals involved become acquainted with one another within that context, the negative impact ceases and may even reverse, but this speculation needs to be tested.

Generalized trust is an important component of democratic citizenship, and our understanding of ourselves as citizens is an ongoing process. Human development consists of a series of transitions, and entering high school is an early step. As such, the transition to high school constitutes an important point when individuals begin to internalize an understanding of society, including if strangers are trustworthy. Our findings suggest that exposure to socioeconomic diversity in the classroom tends to send individuals on a trajectory involving less trust, which in turn has negative consequences for the maintenance of democratic institutions. However, our analysis has data limitations. We cannot be certain regarding the extent to which exposure is an independent effect on generalized trust. Additional data collection that further specifies individual and contextual factors would increase the confidence of our findings. 
Word count 7,787 excluding Endnotes, References, and Tables (4 January 2018)

\section{Endnotes:}

1. Eurostat calculates the Gini coefficient using available income data. The World Bank, using estimates of consumption inequality, produces values that are more moderate although ones that are still higher than the EU average.

2. The High School Soros survey was conducted between October 2010 and May 2011. The study was commissioned by Soros Foundation, Romania, and conducted by Totem Communications. The panel sample was drawn through a random process stratified by type of school (high school and vocational school), cultural region, and locality size (rural, urban $<100,000$, and urban $>100,000$ ). Once a class was selected, all students in that class were asked to respond. The survey conducted in 2010 included 5862 respondents, representing 86 schools from 70 localities. The panel subsample resulted in 2023 respondents, representing 45 schools from 36 localities with an average school size of approximately 500 enrolled students.

3. The Center for the Study of Democracy, Babeş-Bolyai University conducted the EDUCIV survey between May 2006 and May 2009. Using the same sampling procedure (random stratified) as Panel 1, 435 respondents were retained over the three-year period, representing 20 schools from six localities.

4. School level data were collected by the Romanian Agency for Quality Assurance in Pre-university Education (ARACIP) in 2013-2014.

\section{References}

Acemoglu, D., Naidu, S., Restrepo, P. and Robinson, J.A. (2013) Democracy, redistribution and inequality. NBER Working Paper No. 19746 JEL No. O10, P16, http://www.nber.org/papers/w19746.pdf, accessed 17 May 2017.

Alesina, A., and La Ferrara, E. (2005) Ethnic diversity and economic performance. Journal of Economic Literature 43(3): 762-800.

Andolina, M.W., Jenkins, K., Zukin, C. and Keeter, S. (2003) Habits from home, lessons from school: influences on youth engagement. PS: Political Science and Politics 36(2): 275-280.

Baltes, P.B., and Nesselroade, J.R. (1984). Paradigm lost and paradigm regained: critique of Dannefer's portrayal of life-span developmental psychology. American Sociological Review 49(6): 841-847.

Bartels, L. (2016) Unequal Democracy: The Political Economy of the New Gilded Age. Princeton: Princeton University Press.

Benner, A.D. (2011) The transition to high school: current knowledge, future directions. Educational Psychology Review 23(3): 299-328.

Benner, A.D., and Graham, S. (2009) The transition to high school as a development process among multiethnic urban youth. Child Development 80(2): 356-376. 
Bjørnskov, C. (2007) Determinants of generalized trust: a cross-country comparison. Public Choice 130(1): 1-21.

Borgonovi, F. and Burns, T. (2015) The educational roots of trust. OECD Education Working Papers, No. 119, OECD Publishing, Paris. doi: http://dx.doi.org/10.1787/5js1kv85dfvd-en, accessed 17 May 2017.

Borgonovi, F. and Pokropek, A. (2017) Birthplace diversity, incomes inequality and education gradients in generalised trust: the relevance of cognitive skills in 29 countries. OECD Education Working Papers, No. 164, OECD Publishing, Paris. http://dx.doi.org/10.1787/f16a8bae-en, accessed 2 January 2018.

Bourdieu, P. and Passerson, J.C. (1977) Reproduction in Education, Society and Culture. London: Sage Publications.

Bourguignon, F. (2015) The Globalization of Inequality. Princeton: Princeton University Press.

Breen, R. and Jonsson, J.O. (2005) Inequality of opportunity in comparative perspective: recent research on educational attainment and social mobility. Annual Review of Sociology 31: 223243.

Cirino, P.T., Chin, C.E., Sevcik, R.A., Wolf, M., Lovett, M. and Morris, R.D. (2002) Measuring socioeconomic status: reliability and preliminary validity for different approaches. Assessment 9(2): 145-155.

Cohen, J.S., and Smerdon, B.A. (2010) Tightening the dropout tourniquet: easing the transition from middle to high school. Preventing School Failure: Alternative Education for Children and Youth 53(3): 177-184.

Coleman, J.S. (1990) Foundations of Social Theory. Cambridge: Harvard University Press.

Colquitt, J.A., Scott, B.A. and LePine, J.A. (2007) Trust, trustworthiness, and trust propensity: a meta-analytic test of their unique relationships with risk taking and job performance. Journal of Applied Psychology 92(4): 909-927.

Costa, A.C. (2000) A Matter of Trust: Effects on the Performance and Effectiveness of Teams in Organizations. Utrecht: Kurt Lewin Instituut.

Deletant, D. (2015) Romania's commitment to the rule of law. In: L. Stan and D. Vancea (eds.). Post-Communist Romania at Twenty-Five. Lanham, Boulder, New York, and London: Lexington Books, pp. 229-239.

Diamond, L. (1999) Developing Democracy: Toward Consolidation. Baltimore and London: The Johns Hopkins University Press. 
Diamond, L. (2008). The democratic rollback: the resurgence of the predatory state. Foreign Affairs 87(2): 36-48.

Diamond, L. (2015) Facing up to the democratic recession. Journal of Democracy 26(1): 141155.

Dinesen, P.T. and Sønderskov, K.M. (2018) Ethnic diversity and social trust: a critical review of the literature and suggestions for a research agenda. In: E.M. Uslaner (ed.) The Oxford Handbook on Social and Political Trust. Oxford: Oxford University Press. DOI: 10.1093/oxfordhb/9780190274801.013.13

Dinesen, P.T. and Sønderskov, K.M. (2012) Trust in a time of increasing diversity: on the relationship between ethnic heterogeneity and generalized trust in Denmark from 1979 until today. Scandinavian Political Studies 35(4): 273-294.

Elder Jr, G.H., Johnson, M. K., and Crosnoe, R. (2003) The emergence and development of life course theory. In: J. Mortimer and M. Shanahan (eds.). Handbook of the Life Course. New York: Plenum, pp. 3-22.

European Commission. (2017) Gini coefficient of equivalised disposable income - EU-SILC survey. Eurostat: Products Data Sets, http://ec.europa.eu/eurostat/web/products-datasets//tessi190, accessed 17 May 2017.

Fukuyama, F. 1995. Trust: The Social Virtues and the Creation of Prosperity. New York: Free Press.

Fukuyama, F., Diamond, L. and Plattner, M. (eds.) (2012) Poverty, Inequality, and Democracy. Baltimore and London: The Johns Hopkins University Press.

Gallagher, T. (2005) Modern Romania: The End of Communism, the Failure of Democratic Reform, and the Theft of a Nation. New York: New York University Press.

Greskovits, B. (2015) The hollowing and backsliding of democracy in East Central Europe. Global Policy 6(S1): 28-37.

Gustavsson, M. and Jordahl, H. (2008) Inequality and trust in Sweden: some inequalities are more harmful than others. Journal of Public Economics 92(1-2): 348-365.

Heyns, B. (2005) Emerging inequalities in Central and Eastern Europe. Annual Review of Sociology 31: 163-197.

Huber, E. and Stephens, J.D. (2012) Democracy and the Left: Social Policy and Inequality in Latin America. Chicago: The University of Chicago Press.

Hollis, M. (1998) Trust within Reason. Cambridge: Cambridge University Press. 
Jamal, A. and Nooruddin, I. (2010) The democratic utility of trust: a cross-national analysis. The Journal of Politics 72(1): 45-59.

Jung, F. and Sunde, U. (2014) Income, inequality, and the stability of democracy: another look at the Lipset hypothesis. European Journal of Political Economy 35: 52-74.

Kang, W. (2015) Inequality, the welfare system and satisfaction with democracy in South Korea. International Political Science Review 36(5): 493-509.

Keeley, B. (2015) Income inequality: the gap between rich and poor. OECD Insights. Paris: OECD Publishing, doi: http://dx.doi.org/10.1787/9789264246010-en, accessed 17 May 2017.

Knack, S. and Keefer, P. (1997) Does social capital have an economic payoff? A cross-country investigation. The Quarterly Journal of Economics 112(4): 1251-1288.

Knack, S. and Zak, P.J. (2002) Building trust: public policy, interpersonal trust, and economic development. Supreme Court Economic Review 10: 91-107.

Kurlantzick, J. (2011) The great democracy meltdown. New Republic 242(8) 18 May, p. 12.

Langenkamp, AG. (2009) Following different pathways: social integration, achievement, and the transition to high school. American Journal of Education 116(1): 69-97.

Layte, R. (2012) The association between income inequality and mental health: testing status anxiety, social capital, and neo-materialist explanations. European Sociological Review 28(4): 498-511.

Leigh, A. (2006) Trust, inequality and ethnic heterogeneity. Economic Record 82(258): 268-280.

Letki, N. (2006) Investigating the roots of civic morality: trust, social capital, and institutional performance. Political Behavior 28(4): 305-325.

Levitsky, S. and Way, L. (2015) The myth of democratic recession. The Journal of Democracy 26(1): 45-58.

Marschall, M.J. and Stolle, D. (2004) Race and the city: neighborhood context and the development of generalized trust. Political Behavior 26(2): 125-153.

McAllister, D.J. (1995) Affect- and cognition-based trust as foundations for interpersonal cooperation in organizations. Academy of Management Journal 38(1): 24-59.

Milanovic, B. (2013) Global income inequality in numbers: in history and now. Global Policy 4(2): 198-208.

Mudde, C. (2013) Three decades of populist radical right parties in Western Europe: so what? European Journal of Political Research 52(1): 1-19. 
Newton, K. (1999) Social capital and democracy in modern Europe. In: Van Deth, J., Maraffi, M., Newton, K. and Whiteley, P. (eds.). Social Capital and European Democracy. New York, Routledge, pp. 3-24.

Niemi, R.G. and Sobieszek, B.I. (1977) Political socialization. Annual Review of Sociology 3: 209-233.

Olivera, J. (2015) Changes in inequality and generalized trust in Europe. Social Indicators Research 124(1): 21-41.

Piketty, T. (2014) Capital in the Twenty-First Century. Cambridge, MA: Belknap Press.

Prior, M. (2010) You've either got it or you don't? The stability of political interest over the life cycle. The Journal of Politics 72(3): 747-766.

Puddington, A. (2010) The erosion accelerates. Journal of Democracy 21(2): 136-150.

Putnam, R.D. (2000) Bowling Alone: The Collapse and Revival of American Community. New York: Simon and Schuster.

Rahn, W.M. and Transue, J.E. (1998) Social trust and value change: the decline of social capital in American youth, 1976-1995. Political Psychology 19(3): 545-565.

Roine, J. and Waldenström, D. (2015) Long-run trends in the distribution of income and wealth. In: Atkinson, A.B. and Bourguignon, F. (eds.). Handbook of Income Distribution, vol. 2A. Amsterdam: Elsevier, North-Holland Publishing Co., pp. 471-592.

Savoia, A., Easaw, J. and McKay, A. (2010) Inequality, democracy, and institutions: a critical review of recent research. World Development 38(2): 142-154.

Shanahan, M.J. (2000) Pathways to adulthood in changing societies: variability and mechanisms in life course perspective. Annual Review of Sociology 26: 667-692.

Shapiro, S.P. (1987) The social control of interpersonal trust. American Journal of Sociology 93(3): 623-658.

Six, F. (2005) The Trouble with Trust. Cheltenham, UK: Edward Elgar.

Stan, S. and Erne, R. (2014) Explaining Romanian labor migration: from development gaps to development trajectories. Labor History 55(1): 21-46.

Stiglitz, J.E. (2012) The Price of Inequality: How Today's Divided Society Endangers our Future. New York: W.W. Norton.

Stolle, D. and Hooghe, M. (2004) The roots of social capital: attitudinal and network mechanisms in the relation between youth and adult indicators of social capital. Acta Politica 39(4): 422-441. 
Sullivan, J.L. and Transue, J.E. (1999) The psychological underpinnings of democracy: a selective review of research on political tolerance, interpersonal trust, and social capital. Annual Review of Psychology 50: 625-650.

UNICEF Romania (2014) Annual Report, https://www.unicef.org/about/annualreport/files/ Romania_Annual_Report_2014.pdf, accessed 16 May 2017.

Uslaner, E.M. (2002) The Moral Foundations of Trust. Cambridge, MA: Cambridge University Press.

Uslaner, E.M. (2003) Trust and civic engagement in East and West. In: Bădescu, G. and Uslaner, E.M. (eds.). Social Capital and the Transition to Democracy. London and New York: Routledge, pp. 81-94.

Uslaner, E.M. (2011) Trust, diversity, and segregation in the United States and the United Kingdom. Comparative Sociology 10(2): 221-247.

Uslaner, E.M. and Brown, M. (2005) Inequality, trust, and civic engagement. American Politics Research 33(6): 868-894.

Warren, M.E. (ed.) (1999) Democracy and Trust. Cambridge: Cambridge University Press.

Wright, E.O. and Perrone, L. (1977) Marxist class categories and income inequality. American Sociological Review 42(1): 32-55.

Zak, P.J. and Knack, S. (2001) Trust and growth. The Economic Journal 111(470): 295-321. 
Figure 1: Student grade level and trust, with lowest and highest quartiles of inequality shown

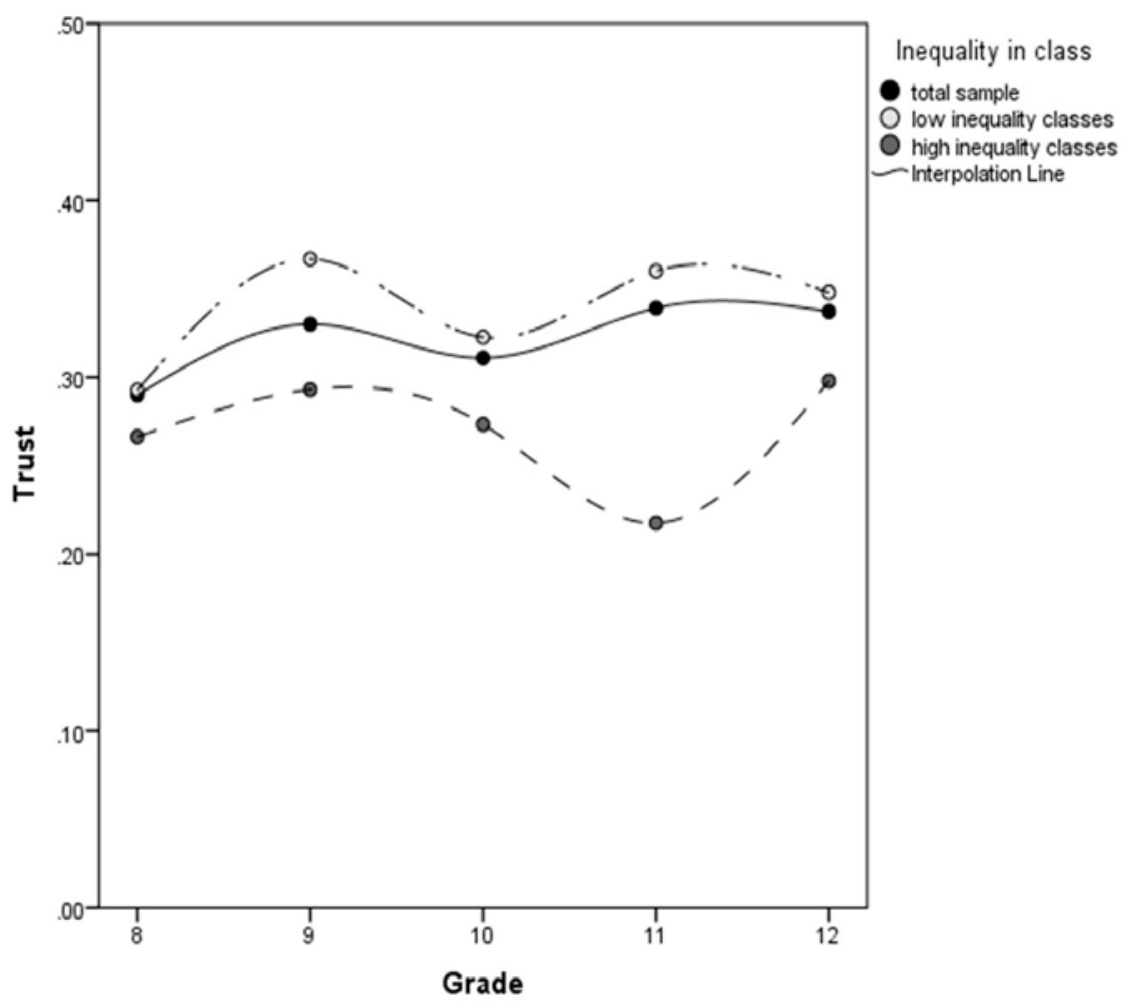


Table 1: Subsample models of generalized trust

\begin{tabular}{|c|c|c|c|c|c|}
\hline \multicolumn{3}{|c|}{$8^{\text {th }}$ grade subsample } & \multicolumn{3}{|c|}{ High school subsample } \\
\hline & std. est. & p-value & & std. est. & p-value \\
\hline Trust $\sim$ & & & Trust & & \\
\hline Inequality (classroom) & .039 & .317 & Inequality (classroom) & -.137 & $* * *$ \\
\hline Family income & -.100 & $*$ & Family income & -.005 & .746 \\
\hline Parental education & .173 & $* * *$ & Parental education & .222 & $* * *$ \\
\hline Family income $\sim$ & & & Family income & & \\
\hline Parental education & .169 & $* * *$ & Parental education & .238 & $* * *$ \\
\hline Error terms & & & Error terms & & \\
\hline t4 & .714 & & t4 & .841 & \\
\hline t3 & .848 & $* * *$ & t3 & .755 & $* * *$ \\
\hline t2 & .3 .60 & $* * *$ & t2 & .325 & $* * *$ \\
\hline $\mathrm{N}=825$ & & & $\mathrm{~N}=5,036$ & & \\
\hline $\mathrm{CFI}=0.989$ & & & $\mathrm{CFI}=0.986$ & & \\
\hline TLI $=0.966$ & & & $\mathrm{TLI}=0.957$ & & \\
\hline RMSEA $=0.031$ & & & RMSEA $=0.038$ & & \\
\hline
\end{tabular}


Table 2: Combined eighth and ninth-grade subsample model of generalized trust model

\begin{tabular}{|l|r|r|}
\hline & std. est. & p-value \\
\hline Trust $~$ & & \\
\hline Inequality (classroom) & -.069 & $* *$ \\
\hline Family income & -.051 & $*$ \\
\hline Parental education & .247 & $* * *$ \\
\hline Ninth-grader & .419 & $* * *$ \\
\hline Ninth-grader*Inequality (classroom) & -.352 & $* * *$ \\
\hline & & \\
\hline Family income $~$ & & \\
\hline Parental education & .249 & $* * *$ \\
\hline & & \\
\hline Error terms $\sim$ & & \\
\hline $\mathrm{t} 4$ & .810 & \\
\hline $\mathrm{t} 3$ & .782 & $* * *$ \\
\hline $\mathrm{t} 2$ & .350 & $* * *$ \\
\hline & & \\
\hline $\mathrm{N}=2,966$ & & \\
\hline CFI $=0.992$ & & \\
\hline TLI $=0.982$ & & \\
\hline RMSEA $=0.043$ & & \\
\hline$* * *=\mathrm{p}-\mathrm{value}<.001 ; * *=$ p-value $<.01 ; *=\mathrm{p}$-value $<.05$
\end{tabular}


Table 3: Subsample models controlling for community inequality and polarization

\begin{tabular}{|c|c|c|c|c|c|}
\hline \multicolumn{3}{|c|}{$8^{\text {th }}$ grade subsample } & \multicolumn{3}{|c|}{ High school subsample } \\
\hline & std. est. & $\mathrm{p}$-value & & std. est. & $\mathrm{p}$-value \\
\hline Trust & & & Trust & & \\
\hline Inequality (classroom) & -.100 & * & Inequality (classroom) & -.115 & *** \\
\hline Locality inequality (educ) & .179 & $* * *$ & Locality inequality (educ) & .088 & *** \\
\hline Locality inequality (housing) & .289 & $* * *$ & Locality inequality (housing) & .065 & ** \\
\hline Locality polarization & -.294 & $* * *$ & Locality polarization & .062 & ** \\
\hline Family income & -.098 & * & Family income & -.019 & 254 \\
\hline Parental education & .075 & 147 & Parental education & .196 & *** \\
\hline University in locality & .094 & $*$ & University in locality & .047 & * \\
\hline Family income & & & Family income & & \\
\hline Parental education & .168 & $* * *$ & Parental education & 278 & *** \\
\hline Error terms & & & Error terms & & \\
\hline $\mathrm{t} 4$ & .729 & & t4 & .836 & \\
\hline t3 & .828 & $* * *$ & $\mathrm{t} 3$ & .760 & $* * *$ \\
\hline $\mathrm{t} 2$ & .360 & $* * *$ & $\mathrm{t} 2$ & .326 & *** \\
\hline $\mathrm{N}=825$ & & & $\mathrm{~N}=5,036$ & & \\
\hline CFI $=0.962$ & & & $\mathrm{CFI}=0.977$ & & \\
\hline TLI $=0.910$ & & & TLI $=0.939$ & & \\
\hline RMSEA $=0.045$ & & & RMSEA $=0.054$ & & \\
\hline
\end{tabular}


Table 4: Combined eighth and ninth-grade model of generalized trust model controlling for community inequality and polarization

\begin{tabular}{|c|c|c|}
\hline & std. est. & p-value \\
\hline \multicolumn{3}{|l|}{ Trust $\sim$} \\
\hline Inequality (classroom) & .017 & .721 \\
\hline Locality inequality (educ) & .095 & $* * *$ \\
\hline Locality inequality (housing) & .113 & $* * *$ \\
\hline Locality polarization & .012 & .745 \\
\hline University in locality & .066 & $* *$ \\
\hline Family income & -.050 & * \\
\hline Parental education & .188 & $* * *$ \\
\hline Ninth-grader & .252 & $* *$ \\
\hline Ninth-grader*inequality (classroom) & -.227 & * \\
\hline \multicolumn{3}{|l|}{ Family income } \\
\hline Parental education & .248 & *** \\
\hline \multicolumn{3}{|l|}{ Error terms } \\
\hline t4 & .804 & \\
\hline $\mathrm{t} 3$ & .785 & $* * *$ \\
\hline $\mathrm{t} 2$ & .348 & $* * *$ \\
\hline \multicolumn{3}{|l|}{$\mathrm{N}=2,966$} \\
\hline \multicolumn{3}{|l|}{$\mathrm{CFI}=0.982$} \\
\hline \multicolumn{3}{|l|}{ TLI $=0.957$} \\
\hline RMSEA $=0.050$ & & \\
\hline
\end{tabular}


Table 5: Longitudinal model using data collected from ninth-grade students

\begin{tabular}{|c|c|c|c|c|c|}
\hline \multicolumn{3}{|c|}{ Panel Model } & \multicolumn{3}{|c|}{ Panel Model with Locality Measures } \\
\hline & $\begin{array}{l}\text { std. } \\
\text { est. }\end{array}$ & $\begin{array}{c}\mathrm{p}^{-} \\
\text {value }\end{array}$ & & $\begin{array}{l}\text { std. } \\
\text { est. }\end{array}$ & $\begin{array}{c}\mathrm{p}^{-} \\
\text {value }\end{array}$ \\
\hline Trust $_{1} \sim$ & & & Trust $_{1} \sim$ & & \\
\hline $\begin{array}{l}\text { Exposure to inequality } \\
\text { (classroom) }\end{array}$ & -.182 & $* * *$ & $\begin{array}{l}\text { Exposure to inequality } \\
\text { (classroom) }\end{array}$ & -.105 & ** \\
\hline Family income & -.017 & .622 & Family income & -.022 & .525 \\
\hline Parental education & .179 & $* * *$ & Parental education & .142 & *** \\
\hline & & & Locality inequality (educ) & .212 & $* * *$ \\
\hline & & & Locality inequality (housing) & .080 & * \\
\hline & & & Locality polarization & -.043 & .308 \\
\hline Trust $_{2} \sim$ & & & Trust $2 \sim_{2}$ & & \\
\hline Trust $_{1}$ & .608 & $* * *$ & Trust $_{1}$ & .584 & $* * *$ \\
\hline $\begin{array}{l}\text { Exposure to inequality } \\
\text { (classroom) }\end{array}$ & -.051 & .080 & $\begin{array}{l}\text { Exposure to inequality } \\
\text { (classroom) }\end{array}$ & -.005 & .871 \\
\hline Family income & -.042 & .160 & Family income & -.043 & .150 \\
\hline Parental education & .092 & $* *$ & Parental education & .073 & * \\
\hline & & & Locality inequality (educ) & .126 & $* * *$ \\
\hline & & & Locality inequality (housing) & .028 & .365 \\
\hline & & & Locality polarization & -.082 & * \\
\hline & & & & & \\
\hline Family income & & & Family income & & \\
\hline Parental education & .230 & $* * *$ & Parental education & .228 & $* * *$ \\
\hline Error terms & & & Error terms & & \\
\hline $\mathrm{t} 4_{1}$ & .840 & & $\mathrm{t} 4_{1}$ & .825 & \\
\hline $\mathrm{t} 3_{1}$ & .752 & $* * *$ & $\mathrm{t} 3_{1}$ & .763 & $* * *$ \\
\hline $\mathrm{t} 2_{1}$ & .300 & $* * *$ & $\mathrm{t} 2_{1}$ & .302 & $* * *$ \\
\hline $\mathrm{t} 4_{2}$ & .872 & & $\mathrm{t} 4_{2}$ & .864 & \\
\hline $\mathrm{t} 3_{2}$ & .783 & $* * *$ & $\mathrm{t} 3_{2}$ & .788 & $* * *$ \\
\hline $\mathrm{t} 2_{2}$ & .306 & $* * *$ & $\mathrm{t} 2_{2}$ & .306 & $* * *$ \\
\hline $\mathrm{N}=1,250$ & & & $\mathrm{~N}=1250$ & & \\
\hline CFI $=.993$ & & & $\mathrm{CFI}=0.979$ & & \\
\hline TLI $=0.982$ & & & TLI $=0.955$ & & \\
\hline RMSEA $=0.028$ & & & RMSEA $=0.035$ & & \\
\hline
\end{tabular}




\section{Appendix: Variable Specifications and Descriptive Statistics}

\begin{tabular}{|c|c|c|c|c|c|c|c|}
\hline Variable & Definition & \# obs & Mean & $\begin{array}{l}\text { Std } \\
\text { dev }\end{array}$ & Min & Max & Source \\
\hline Trust1 & 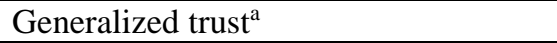 & 5862 & 0.36 & 0.23 & 0 & 1 & RO survey \\
\hline Trust 2 & Generalized trust & 2023 & 0.37 & 0.22 & 0 & 1 & RO panel ${ }^{b}$ \\
\hline Grade & Grade school & 5862 & 9.84 & 1.31 & 8 & 12 & RO survey \\
\hline Ninth-grader & $\begin{array}{l}\text { Dummy variable coded } 1 \text { for } 9 \text { th } \\
\text { graders, } 0 \text { for } 8 \text { th graders }\end{array}$ & 5862 & 0.72 & 0.13 & 0 & 1 & RO survey \\
\hline Family income & Subjective income $(0-1)$ & 5862 & 0.58 & 0.18 & 0 & 1 & RO survey \\
\hline Parental education & Mean level of parents' education & 5862 & 0.40 & 0.25 & 0 & 1 & RO survey \\
\hline Ineq. classroom & $\begin{array}{l}\text { St. dev. of family income at class } \\
\text { level }\end{array}$ & 5862 & 0.17 & 0.04 & 0.06 & 0.33 & RO survey \\
\hline $\begin{array}{l}\text { Locality inequality } \\
\text { (educ) }\end{array}$ & $\begin{array}{l}\text { Std. dev. of the number of years of } \\
\text { school at locality level }\end{array}$ & 5862 & 0.76 & 0.14 & 0.20 & 0.94 & Census 2012 \\
\hline $\begin{array}{l}\text { Locality inequality } \\
\text { (housing) }\end{array}$ & $\begin{array}{l}\text { Std. dev. of the apartment size at } \\
\text { locality level }\end{array}$ & 5862 & 287.08 & 28.61 & 211.87 & 410.10 & Census 2012 \\
\hline $\begin{array}{l}\text { Locality } \\
\text { polarization }\end{array}$ & $\begin{array}{l}\text { Std. dev. of the difference between } \\
\text { the \% of students in each 0-8 level } \\
\text { school with at least one parent whose } \\
\text { education level is less than 8th grade } \\
\text { completed, and the \% of students with } \\
\text { at least one parent with higher } \\
\text { education. }\end{array}$ & 5862 & 0.42 & 0.09 & 0.24 & 0.65 & ARACIP $^{c}$ \\
\hline $\begin{array}{l}\text { University in } \\
\text { locality }\end{array}$ & $\begin{array}{l}\text { University in locality }(0=\text { none, } 1= \\
\text { small, } 2=\text { medium, } 3=\text { large })\end{array}$ & 5862 & 0.55 & 1.31 & 0 & 3 & ARACIS $^{d}$ \\
\hline
\end{tabular}

Notes: a: Generalized trust is measured as a latent variable from three observed measures: 1 ) trust in people one meets for the first time, 2) trust in people who possess a faith different from one's own, and 3) trust in other ethnicities.

b: Survey 1B is the second wave of a panel subsample of Survey 1.

c: Data collected by the Romanian Agency for Quality Assurance in Pre-university Education (ARACIP) in 2013-2014.

d: Data collected by the Romanian Agency for Quality Assurance in Higher Education (ARACIS) in 20132014. 